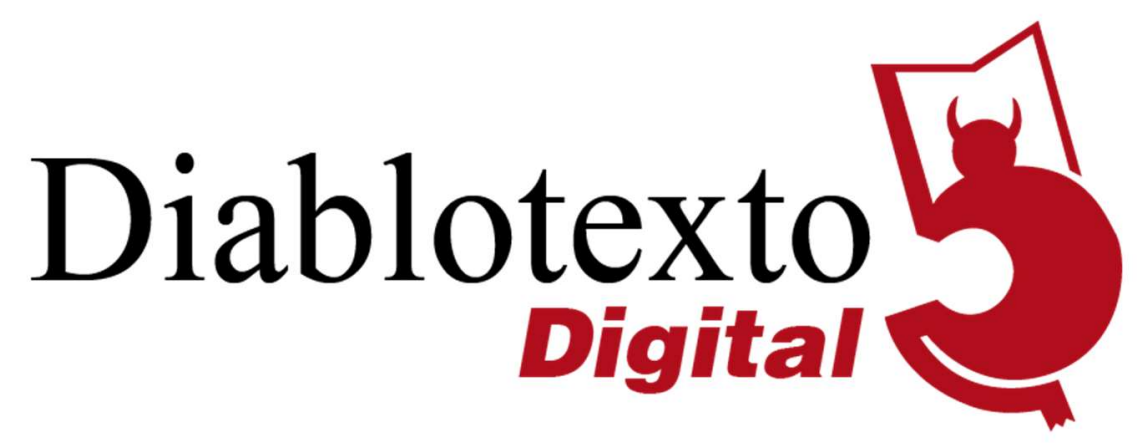

\title{
Enfrentarse a la violencia: metateatro como mecanismo revelador en Himmelweg, de Juan Mayorga, y El triángulo azul, de Mariano Llorente y Laila Ripoll
}

Facing Violence: Metatheatre as a Revealing Mechanism in Himmelweg, by Juan Mayorga, and El triángulo azul, by Mariano Llorente \& Laila Ripoll

\section{PABLO SÁNCHEZ HERNÁNDEZ UNIVERSIDAD COMPLUTENSE DE MADRID}

Resumen: El metateatro se ha utilizado a lo largo de la historia del teatro. Sin embargo, en el siglo XX y, posteriormente, en el siglo XXI, al ser nombrado, se ha empezado a utilizar de una manera más consciente. Fruto de esta proliferación ha aparecido una gran cantidad de producciones escénicas en España que utilizan este recurso para presentar el horror de la barbarie. Entre todas ellas, este artículo pretende realizar un estudio comparativo entre Himmelweg, de Juan Mayorga, y El triángulo azul, de Mariano Llorente y Laila Ripoll. Se atenderá especialmente a los signos teatrales relacionados con el espacio sonoro, el espacio o el tiempo.

Palabras clave: teatro español, Memoria, metateatro, dramaturgia contemporánea

Abstract: Metatheatre has been used along theatre's history. Nevertheless, in $X X^{\text {th }}$ Century and, subsequently in XXI ${ }^{\text {st }}$ Century, due to his naming, it has started to be used more consciously. Because of this blooming, a great number of escenic works, which has appeared in Spain recently, has been using this resource to present the horror resulting from barbary. Among them, this article tries to make a comparative study between Himmelweg, by Juan Mayorga, and El triángulo azul, by Mariano Llorente \& Laila Ripoll, focusing on the theatrical signs related to sound design, space or time.

Key words: Spanish Theatre, Memory, metatheatre, contemporary dramaturgy 
A lo largo del siglo $X X$ se han representado diferentes obras de teatro cuyo fin es recordar la memoria de las víctimas que han sufrido la barbarie de las guerras que acontecieron durante este siglo, como son las dos guerras mundiales o la Guerra Civil Española. Este tipo de producciones artísticas se apoya, directa o indirectamente, en una serie de ideas filosóficas que han ido evolucionando, sobre todo, a partir de la figura de Walter Benjamin. Este filósofo judío y alemán escribió una serie de textos denominados tesis Sobre el concepto de Historia, donde se puede observar el planteamiento de un nuevo historiador que no se deja llevar por el relato oficial, ni por una necesidad incesante de progreso, sino que, como un trapero, va buscando las historias de aquellos que han sido puestos en los márgenes o aplastados, condenados al Olvido.

La huella de Benjamin impresa en sus sucesores se puede constatar en el teatro español de finales del pasado siglo y principios del actual, sobre todo visible a partir de la aparición de José Sanchis Sinisterra ${ }^{1}$. Precisamente este mismo autor acuña el nombre de un cambio de paradigma en la manera de representar la historia:

El teatro, que siempre pretende hablar a sus contemporáneos, se vuelve a menudo hacia el pasado para nutrir el presente, para dotarlo de raíces, de sentido, de densidad. A las obras surgidas de esta mirada retrospectiva se las suele llamar "históricas", pero a mí, francamente, esta denominación me parece un poco solemne y acartonada. En vez de usar el pretencioso término de "teatro histórico", yo prefiero hablar de "teatro de la memoria" (Sanchis Sinisterra, 2002: 9)

Tras tomar al dramaturgo valenciano como uno de sus referentes, ciertos creadores han seguido sus pasos y han tratado de dar cuenta del horror que supuso la Segunda Guerra Mundial para ciertos españoles y para la humanidad en su totalidad. Entre todos ellos, en este artículo se pretende reflexionar sobre la manera en que dos obras contemporáneas lo representan: Himmelweg (2003), de Juan Mayorga, y El triángulo azul (2014), de Mariano Llorente y Laila Ripoll. En concreto, me centraré en aquellos mecanismos metateatrales que se utilizan

\footnotetext{
1 Hay que tener en cuenta que hay una serie de autores anteriores que escriben en torno a la Memoria, cuya producción se ha denominado Teatro Underground, entre otras denominaciones (neovanguardia, Nuevo Teatro, etc.), que no ha tenido su reconocimiento al no representarse en los escenarios. Se decide poner a Sanchis Sinisterra como referente, en este caso, porque se le entiende como introductor de esta nueva manera de hacer teatro en el circuito comercial.
} 
en ambas obras para poner en escena esa historia acallada de los vencidos que aún pertenece a lo desconocido.

\title{
Una breve aproximación al metateatro en los siglos XX y XXI
}

A lo largo de la historia, el empleo del metateatro ha resultado clave en el desarrollo de ciertas creaciones dramáticas. Un buen ejemplo de ello es el uso que se hace de este mecanismo teatral a lo largo de los Siglos de Oro². A pesar de la gran importancia que tienen estos textos en la actualidad, incluso en las dos obras que se analizan en este artículo, cabe tener en cuenta el devenir del metateatro en el último siglo para entender las variaciones socio-históricas y filosóficas que afectan de manera más directa en la escritura de Himmelweg y El triángulo azul; dado que estas obras no dejan de ser textos dramáticos muy apegados a la realidad y preocupaciones de la contemporaneidad.

A lo largo del siglo $X X$ se comienza a representar una idea que ya se empezó a teorizar a finales del XIX, la impronta que tiene la "teatralidad" en el desarrollo del arte y, por ende, la espectacularización de las creaciones. También se replantea el teatro como un arte independiente de la literatura, lo que ha conseguido que los Estudios Teatrales se emancipen de manera progresiva de un planteamiento logocéntrico. Por tanto, precisamente en este concepto de "teatralidad" reside la causa de la evolución de la producción teatral tanto teórica como práctica en el siglo XX y XXI. Según Óscar Cornago Bernal (2005: 161), esto se debe a que

\begin{abstract}
las estrategias de teatralidad suponen una respuesta a la crisis epistemológica que caracteriza la Modernidad [...]. Lo paradójico es que, como resultado de esta crisis, el propio discurso, como la historia o la subjetividad, se pongan en escena ellos mismos en un ejercicio de metaficción que les haga encontrar algún punto de verdad.
\end{abstract}

Con lo cual, se asume la artificialidad del teatro de manera explícita para la trasmisión de un discurso de autenticidad. Por tanto, mediante la

\footnotetext{
2 En numerosas obras escritas durante este periodo, el metateatro se convierte en el motor dramático para la resolución de la trama. Esto es, adquiere el valor de desvelador. Por nombrar algunos ejemplos, téngase en cuenta: el paradigmático El gran teatro del mundo de Calderón de la Barca; de entre las muchas obras de Lope de Vega, Lo fingido verdadero y Don Gil de las calzas verdes de Tirso de Molina.
} 
metateatralidad, la dramaturgia contemporánea trata de crear un espectador consciente de que el teatro es teatro. Al fin y al cabo, se genera una nueva comunicación teatral que intenta volver al uso ritual de alta significación social como demandaba Georg Fuchs en su manifiesto de 1905 para conseguir "reteatralizar el teatro" (Cornago Bernal, 2003: 26). De hecho, aunque el metateatro ha existido con anterioridad, como ya se ha mencionado antes, hasta el pasado siglo no se acuña el término ${ }^{3}$ y se debate teóricamente sobre ello. Así mismo, la reflexión sobre este concepto conlleva la afloración de su práctica en la escena contemporánea.

Tras ver las coordenadas histórico-culturales en las que se comprende la creación teatral actual, resulta necesario dar una definición de "metateatro" para explicar el punto de partida terminológico de esta investigación, ya que produce una ambigüedad en sus amplias acepciones. He seleccionado la realizada por Patrice Pavis ([1996] 1998: 288-289) en su Diccionario del teatro, que reza lo siguiente: "teatro cuya problemática está centrada en el teatro. [...] No es necesario [...] que estos elementos teatrales formen una obra dentro de la primera. Basta con que la realidad descrita aparezca como ya teatralizada".

Igualmente, se debe señalar las implicaciones que tiene el metateatro como forma de expresión escénica, pues, como refleja María Pilar Jordán Peinado (2016: 14), Schmeling y Hornby manifiestan que la principal función del metateatro es

revelarnos la verdad oculta de unas determinadas circunstancias: de la misma manera que se nos desvelan los mecanismos convencionales de los que se sirve el teatro así también nos enteramos de sucesos históricos ocultados o situaciones injustas.

Lo cual, engarza de manera directa con la finalidad de la dramaturgia que versa sobre la barbarie cometida a lo largo del siglo XX, en especial la perpetrada por la Alemania nazi. Tras este argumento se esconde la posibilidad que tienen los dramaturgos que no han sido testigos del conflicto para poder salvar ese material

\footnotetext{
${ }^{3}$ El término metatheatre aparece por primera vez en 1963 en el libro escrito por Lionel Abel titulado Metatheatre: A New View of Dramatic Form.
} 
no biográfico (Amo Sánchez, 2020)4. En definitiva, se puede entender el metateatro, avalado desde la teoría, como medio para desvelar una realidad que ha sido ocultada. Esta concepción resulta clave en el corpus teatral de la memoria del siglo $\mathrm{XXI}^{5} \mathrm{y}$, en concreto, en el que se tratará en este artículo.

\section{El artefacto de la Shoah ${ }^{6}$}

Himmelweg, escrita por el dramaturgo madrileño Juan Mayorga, se estrenó el 17 de octubre de 2003 en el Teatro Alameda de Málaga. La obra, dividida en cinco partes ${ }^{7}$, a las que me referiré como actos para facilitar la lectura del artículo, nos presenta el artefacto dramático que se efectuó en un campo de concentración y que logró engañar a un Delegado de la Cruz Roja para que este diera un informe positivo sobre lo allí sucedido. La fábula se inspira en los hechos reales que acontecieron en el campo de Teresienstadt en 1944, aunque ninguno de los personajes aparte del Delegado tiene un referente histórico claro. $\mathrm{Ni}$ siquiera Mayorga decide nombrar a los personajes como las personas reales que participaron en este hecho histórico, sino que realiza una ficción especulativa para desvelar la verdad ocultada de la atrocidad ocurrida. Como reflexionó el autor en una entrevista con Fermín Cabal (2009: 444-445), se podría encontrar la razón de evitar un apego fiel a lo sucedido en que él continuamente se interroga sobre la posibilidad de representar el Holocausto y lo que ello conlleva,

\footnotetext{
${ }^{4}$ Agradezco enormemente a Antonia del Amo Sánchez por mandarme el manuscrito ganador del XII Premio Internacional de Investigación Artez Blai sobre las Artes Escénicas que actualmente está en proceso de impresión y será publicado por la editorial vasca Artezblai.

${ }^{5}$ Ya en el siglo XX encontramos ejemplo de este corpus con obras como El álbum familiar (1982), de José Luis Alonso de Santos, o ¡Ay, Carmela! (1987), de José Sanchis Sinisterra. Sin embargo, en nuestro siglo el número de obras se ha multiplicado. Algunos ejemplos de los últimos años, entre muchos otros, son: Dentro de la tierra (2007), de Paco Bezerra, Los perros en danza (2010), de María Velasco; Los Gondra (una historia vasca) (2017), de Borja Ortiz de Gondra; o Mi película italiana (2019), de Rocío Bello. Mención especial debe darse a la publicación en 2019 de Teatro contra el olvido editada por Primer acto con la colaboración del Nuevo Teatro Fronterizo que dirige Sanchis Sinisterra, en el que se antologa una serie de obras que tratan precisamente de rescatar la Memoria de las víctimas.

' Se utiliza del término 'Shoah' frente al conocido 'Holocausto', puesto que los judíos lo prefieren para referirse a este hecho histórico.

${ }^{7}$ Como se puede observar en la división estructural de la obra, posee gran importancia la Poética de Aristóteles en el texto, aunque en este artículo no haré alusión a ello. Para más información sobre este tema consúltese: BRIGNONE, German (2017). "Huellas de la poética de Aristóteles: teoría y práctica metadramática en Himmelweg". En Germán Brignone, Tránsitos, apropiaciones y transformaciones: Un modelo de cartografía para la dramaturgia de Juan Mayorga. Madrid: Consejo Superior de Investigaciones Científicas, 143-148 pp.
} 
así como sobre la legitimidad que tiene para hablar de aquellas víctimas concretas.

Los cinco actos de los que se compone la obra no se distribuyen lógica, ni cronológicamente. De hecho, el primer y el tercer acto resultan ser dos amplios monólogos que se pronuncian al público desde un lugar indeterminado y que, aunque pueden ordenarse cronológicamente dentro de la fábula, no tienen un tiempo concreto. El primero de ellos, que se encuentra al inicio de la obra, refleja la confesión del Delegado sobre lo presenciado en el campo de concentración y de las razones que le llevaron a redactar un informe positivo de lo que allí ocurría. Este monólogo funciona como introito de lo que se observará posteriormente. Por ello, el personaje intenta que el espectador empatice con su postura para la consideración de lo potencialmente cómplices que somos de la barbarie, incluso hoy en día. En este personaje, Juan Mayorga refleja una conducta extendida en la sociedad, ya que este individuo "quiere ser bueno, y sabe que para serlo necesita la verdad, pero prefiere creer lo que dicen" (Mayorga, 2016: 322). El Delegado representa la figura opuesta a la misión que tendría el teatro y la filosofía para Mayorga, con un afán similar a la de Walter Benjamin: tratar de recrear una historia de los vencidos, es decir, dirigirse a lo Olvidado. Desde este momento ya se empieza a vislumbrar la necesidad de mover al espectador a la reflexión en una especie de autoexamen.

El segundo monólogo se sitúa en el tercer acto, en este caso no es el Delegado el encargado de hablar al público, sino el Comandante del campo de concentración. Este personaje recibe a una especie de grupo de delegados, ficcionalización de los espectadores. Se crea un público-otro en la ficción encarnado por el público real que juega, interpreta y actúa en ella, un acto más de metateatro que acerca al espectador a la realidad del escenario y le confiere un papel decisivo. Como consecuencia, repercute en la recepción personal de la obra, ya que el Comandante representa una suerte de demiurgo que intenta hallar cómplices entre el público con el fin de advenirlos a su causa, es decir,

\footnotetext{
8 Este hecho no es baladí, pues el propio Mayorga realizó su tesis doctoral alrededor del pensamiento de este filósofo y del de sus contemporáneos. Una versión revisada y acortada de ella se puede consultar en MAYORGA, Juan (2003) Revolución conservadora y conservación revolucionaria: politica y memoria en Walter Benjamin. Barcelona: Anthropos.
} 
utilizar a los judíos como marionetas, para su posterior exterminio. En definitiva, se intenta buscar aquellos puntos que acerquen al espectador a una ideología nazi que, si el espectador acepta, finalmente tenga una función catártica y se emancipe de ella.

De esta manera, el dramaturgo consigue dos propósitos. En primer lugar, que no quede tan lejana la postura del Delegado, expuesta en el primer acto; lo que permite que el espectador no se mantenga en un estado de pasividad. Se produce, por tanto, una conexión semántica entre ambos actos, lo cual clarifica el recorrido mental que el espectador modelo hace a lo largo de la representación. Esto deriva, en segundo lugar, en su afán de buscar una escritura que se parezca a la de Walter Benjamin: "una escritura tremendamente tensa que una y otra vez se discuta a sí misma" (Cabal, 2009: 439).

El montaje del Centro Dramático Nacional, a pesar de que recibió críticas muy severas (Aznar Soler, 2016) y que tampoco cuenta con el beneplácito del autor (Cabal, 2009: 445), contiene ciertas decisiones artísticas reseñables a la hora de potenciar ciertos signos, aunque descuide otros. Durante el monólogo del tercer acto se encuentra en escena un gran telón que oculta todo el escenario salvo la corbata, lugar donde se desarrolla la acción en el resto de los actos. Este elemento escénico convierte al Comandante en presentador de una obra que jamás veremos representada, aunque el público sí presencia el proceso de preproducción y ensayos. Remarca la intención metateatral de la obra y a la vez vela ante los ojos del espectador el exterminio que allí se produce.

Es importante señalar que el Comandante no solo intenta hacer al espectador cómplice de la barbarie de una manera sutil en el tercer acto, sino que también continuará con esta empresa durante el cuarto. Este personaje conversará con Gottfried, un judío que es escogido para ayudarle y para interpretar el papel de alcalde. A lo largo de las distintas escenas consigue convertirlo en una especie de cómplice debido a sus tareas, como escoger qué judíos sobreviven y cuáles no, obligándole a ejercer actos de violencia contra su propio pueblo. Aunque ocurre de manera asidua, hay una escena en la que, a pesar de hablar a Gottfried, el Comandante interpela al público directamente. Espera que el espectador se quede maravillado por su amplio conocimiento 
cultural al ver su amplia biblioteca. Este hecho potencia el carácter metateatral de la obra, pues menciona a autores como Shakespeare o Calderón. Esta relación con el teatro isabelino inglés y el áureo español desempeña una doble función. Por un lado, señala la importancia que tiene el metateatro en el esqueleto vertebrador de la obra, pues, como ya mencioné antes, esta época utilizaba este mecanismo dramático, sobre todo, Calderón con su idea filosófica del theatrum mundi. Por otro lado, también demuestra lo ya teorizado por Mayorga (2016: 25), pues "una sociedad de lectores, una sociedad que llene museos, una sociedad que abarrote los teatros, puede aplaudir el genocidio. A menos que esa sociedad se sitúe críticamente respecto de su cultura". Con lo cual, lo único que nos libra de la barbarie reside en ser críticos con lo que consumimos artísticamente, idea troncal de la obra mayorguiana.

Más allá de los casos anteriores, el rasgo metateatral más evidente de esta obra se da en el segundo acto, donde se producen los ensayos de la obra que se escenificaría en el campo ante el Delegado. Se puede entender como tal gracias a la repetición constante de los mismos diálogos en múltiples escenas. En ellas se producen siempre pequeñas modificaciones, que transitan desde el cambio de algunas palabras hasta la desaparición de los distintos actores-judíos. A lo largo de este acto, se intercambia continuamente a los niños por otros al equivocarse en sus escenas. El destino final de los desechados se indica mediante el humo que se atreven a ver algunos de los personajes. Sin embargo, el ejemplo más paradigmático es el de la actriz-judía pelirroja, la cual desafía el orden nazi al ser la única que interrumpe el ensayo para mencionar ese humo producido por los hornos. Como respuesta en la siguiente escena aparece esta acotación: "ELLA ES OTRA, Y NO ES PELIRROJA" (Mayorga, 2011: 147). Consigue, pues, tener el mismo destino que aquellos actores-judíos infantiles y, de esta manera, aunque no explícitamente, el espectador puede observar la barbarie. Sin embargo, como en el caso del Delegado, solo puede contemplarla si quiere entender lo que está ocurriendo verdaderamente en el campo de concentración que aparece en escena.

El anterior no es el único acto de rebeldía en la obra: la Niña también se enfrenta al Comandante simbólicamente. Este personaje se revelará al final de 
la obra como hija de Gottfried. En ese momento se le pondrá el nombre de Rebeca y se desvela que ella cambia su intervención diciendo: "Escapa, Rebeca, que viene el alemán" (Mayorga, 2011: 169). Aunque no consigue llamar la atención del Delegado, el público puede escuchar su grito de auxilio. Nuevamente queda a decisión del espectador seguir, como el Delegado, sordo a las palabras de la niña o, sin embargo, que se deje cautivar ${ }^{9}$ por el silencio provocado por la ausencia para poder llegar a una recuperación de la Memoria.

Rebeca vuelve a jugar un papel importante al final de la obra. Tras acabar uno de los ensayos, canta una canción ${ }^{10}$ que Mayorga no especifica, queda en cada director la libre elección de escoger qué nana cantar en su montaje. Mayorga construye la obra en torno a la escucha de ese silencio posterior a la canción, "el silencio de la vida interrumpida, el silencio de la vida que podía haber sido" (Sánchez Hernández, 2018) ${ }^{11}$. Este canto sume la obra en el tiempo mesiánico del que habla Benjamin, es decir, un presente que mira al pasado para poder avanzar al futuro, un tiempo de redención y de revolución (Mate y Mayorga, 2001: 55). Esta última canción no salva en ningún momento a las víctimas de esa muerte física, pero sí permite que el espectador que ha escuchado el silencio recupere la Memoria de todas ellas y no haya una segunda muerte simbólica, con lo que se evita en un futuro reproducir la barbarie ocurrida en escena.

Todo este artificio metateatral se materializa en el símbolo del reloj de la plaza situado dentro del campo, el cual ha estudiado de manera extensa Enrico Di Pastena (2010). Las fechas que lo rodean son clave para su determinación como tal. En primer lugar, fue fabricado en Núremberg, ciudad donde fue juzgada una gran cantidad de altos cargos nazis tras la Segunda Guerra Mundial. En segundo lugar, Gottfried cita el año 1914, fecha de comienzo de la Primera Guerra Mundial y en la que se reactiva la cuestión antisemita en Europa, más en concreto, en Alemania. Por último, se menciona la Toledo de 1492, fecha en la

\footnotetext{
9 Es interesante señalar que, según su etimología, el nombre de 'Rebeca' proviene de 'cautivadora', aunque signifique 'mujer llena de gracia'.

10 Señálese que esta canción ha sido referenciada en varias ocasiones a lo largo de la obra, pero hasta este momento no cobra sentido pleno (Johnson, 2016: 302).

11 Estas palabras forman parte de una entrevista inédita que el propio Juan Mayorga me concedió.
} 
que se expulsó a los judíos de España. En consecuencia, a ese reloj no solo se le asocia el mecanizado gobierno nazi, sino también el aplastamiento del pueblo judío a lo largo de su historia. Se convertiría en un documento de cultura que es a la vez de barbarie, como expone Benjamin en su tesis VII (Mate, 2009: 130). Este pensamiento se conecta con esa idea expuesta sobre la biblioteca del Comandante, pues aquí el documento-reloj adquiere una función de opresión en detrimento de las víctimas. El dramaturgo desvela, sin ninguna duda ya, la significación que posee el recurso de la metateatralidad para llegar a entender la obra; y, en extensión, denuncia el posible engaño creado por aquel que tiene el poder de escribir el relato oficial.

En «Razón del teatro», incluido en Elipses, Juan Mayorga (2016: 98) invita a concebir un teatro que la barbarie no pueda utilizar. Precisamente en Himmelweg, en ningún momento se pone en escena aquel teatro que pudiera ser usado con fines violentos, sino que descompone ante los ojos del espectador el artificio que crea el Comandante. Como bien expone John P. Gabriele (2014: 58), "la realidad que pinta Mayorga en Himmelweg está rodeada de un aura de artificialidad porque el pasado a que se refiere no ha sido asimilado en la conciencia humana individual y mundial". Se intenta con el metateatro de la obra crear una tensión en el espectador, independientemente de su formación cultural, para que decida abandonar el relato oficial de la Historia o, sin embargo, continúe queriendo ser engañado conscientemente como el Delegado de la Cruz Roja.

\section{Una revista española en medio de la barbarie}

El triángulo azul, escrita por los dramaturgos Mariano Llorente y Laila Ripoll, se estrenó el 25 de abril de 2014 en la Sala Francisco Nieva del Teatro Valle-Inclán con dirección de la propia co-autora. La obra ganadora del Premio Nacional de Literatura Dramática en 2015 representa la vida de un grupo de españoles republicanos apátridas que fueron hacinados en el campo de concentración nazi de Mauthausen. Un episodio de la historia de nuestro país que todavía continúa siendo desconocido para la mayoría de los españoles.

El componente metateatral se puede encontrar incluso desde el planteamiento dramatúrgico. En primer lugar, El triángulo azul se presenta como 
la rememoración de Ricken ${ }^{12}$, el alemán encargado del departamento de fotografía en el campo de concentración donde se sitúa el resto de la acción dramática. Ricken conversa con sus hijos, el público ficcionalizado de nuevo, sobre lo acontecido en el campo. La obra culminará con su propio suicidio tras haber completado su confesión. Aparte de este marco y la trama principal, dedicada a la operación de sustracción de fotografías que sirvieron como pruebas en los juicios de Núremberg, la obra toma como vertebrador formal un hecho insólito acontecido en este mismo campo. En las Navidades de 1942, los presos españoles consiguieron que se realizara dentro de él una revista llamada El Rajá de Rajayola. Esto permite que a lo largo de la obra se encuentren una serie de números musicales que muestran las distintas barbaridades que fueron cometidas por la Alemania nazi. Se consigue de esta forma encarnar de una manera teatral aquello que las fotografías ayudaron a desvelar.

Resulta interesante que, como estudia Cristina Oñoro Otero (2016), precisamente los números de revista se asocien a distintas canciones populares, mientras que las canciones cultas, en especial la suite $N^{0} 1$ en Sol Mayor para violonchelo de Bach, se relacionan con el bando nacionalsocialista. Por tanto, se produce una correspondencia entre la barbarie y lo canónico, pues es lo que sobrevive, lo que sigue venciendo sobre lo marginal; mientras que en lo popular se proyecta un acto de resistencia contra el poder absoluto. En el ámbito de lo popular se puede rastrear la historia de las víctimas, pues se convierte en el medio que poseen para poder expresar sus inquietudes y problemas. De esta manera, los fragmentos musicalizados adquieren el valor de una suerte de contra-archivos culturales. Se observa, por consiguiente, la idea benjaminiana, aplicada con anterioridad a Himmelweg, de que el documento de cultura se entiende como documento de barbarie, puesto que simplemente se refleja el relato de los vencedores. Se produce, pues, una contraposición entre cultura y contra-cultura, esta última favorecida, además, por la existencia de contraarchivos como las fotografías.

12 El nombre de Ricken se tomó directamente de la persona real que se ocupaba del departamento de fotografía en el campo de Mauthausen; así como también los nombres de Paco y Toni, que se basan en aquellos españoles reales que trabajaron allí: Francisco Boix y Antonio García Alonso. 
La co-autora y directora de El triángulo azul ha manifestado en numerosas ocasiones su fascinación por la estética de dramaturgos como Francisco Nieva o de compañías de teatro como La Zaranda (Cabal, 2009: 458, 476). Por ello, explora la estética del grotesco investigada por estos autores que, como bien analiza Cornago Bernal ([1999] 2000), genera una visión de lo popular desde un distanciamiento que revela la cruda realidad mediante el juego y la hiperbolización esperpéntica. Este planteamiento estético facilita a los escritores investigar una vía peculiar de distanciamiento: la risa incómoda. Mediante el juego metateatral se incluyen distintos chistes con un matiz de lo que podríamos llamar humor negro, como, por ejemplo: "A ver: ¿qué hace un pescado en un teatro? ¡Ser un mero espectador!” (Llorente y Ripoll, 2014: 54), para a continuación Ricken añadir: "Y es que en la Navidad de 1942 casi un setenta por ciento de los españoles que entraron en Mauthausen ya habían sido asesinados" (Llorente y Ripoll, 2014: 54). La risa provocada por este tipo de humor es definida por Isabelle Reck (2012: 78) como aquella

que invita al espectador/lector primero a abandonarse a la carcajada franca, para dejarle atragantarse de pronto, de manera desprevenida, y conducirle al final a una risa crispada, una risa que lo desestabiliza, lo deja perplejo, lo compromete y le hace sentir incómodo.

Esta risa genera, pues, una serie de contradicciones que llevan al extrañamiento y a la reflexión, ya que este humor no está pensado "nunca para soslayar el efecto de horror, sino más bien para consentir que el espectador descubra lo que hay detrás de la máscara del poder, hasta del mismo Hitler" (Trecca, 2016: 255). Se observa también en esta obra la necesidad de que haya un público activo que sea consciente de lo ocurrido en el campo y no decida simplemente abandonarse a la risa, sino que la risa lleve a la reflexión.

En un fragmento del montaje que dirigió la propia Laila Ripoll en el Centro Dramático Nacional se puede observar una escena surrealizante en la que se asiste al ahorcamiento de un austriaco, acción dramática basada en un hecho real. Durante este momento, de gran carga trágica, se produce una contraposición mediante diferentes códigos escénicos, pues ante el horror de lo ocurrido suena una música alegre que acompaña durante toda la escena. Junto a este espacio sonoro, aparece un anacrónico controlador de tráfico que anima 
al público en todo momento a dar palmas. Esto provocaría un efecto similar a la risa nerviosa, pues permite experimentar la sensación de dejarse llevar por la barbarie mediante la espectacularidad, para después hacer consciente al espectador del hecho representado. Además, demuestran que el uso de lo grotesco en estos números musicales fue el recurso que les permitió "hablar del horror, de lo inimaginable, de la bestialidad del campo... de cosas que, de otra manera, sería imposible hablar por espantosas" (Centro Dramático Nacional, 2013: 25).

La utilización de distintos códigos contrapuestos se puede observar también en una ocasión en la que Brettmeier, el alto cargo de las SS que dirige el campo, habla a una prostituta gitana recluida para disfrute de los hombres que habitan allí: "Dentro de unos años no quedará ninguno de vosotros en Europa, pero si pudiera, me guardaría para mí una mujer y una orquesta de gitanos para que me recuerden el sabor de la inmundicia" (Llorente y Ripoll, 2014: 35-36). Ante este ataque de odio hacia la raza gitana se descubre una música redentora con la siguiente acotación: "Y la orquesta gitana se arranca con alegría" (Llorente y Ripoll, 2014: 36). De esta manera, el acto de violencia verbal se sustituye por una música que reivindica la figura de otros colectivos exterminados en los campos de concentración nazis, además de a los republicanos españoles, pudiendo llegar a escribir una historia total de las víctimas como anunciaba Benjamin.

Por último, se ha de destacar el intertexto utilizado en algunos de estos números que suspenden el orden lógico de la fábula, y que, nuevamente, sirven como ejemplos de la metateatralidad inherente a la obra. No hay que olvidar que la compañía Micomicón, fundada entre otros por los dos autores de esta obra, nació con el fin de representar teatro áureo español. Esta experiencia repercute en que para enlistar las "treinta y cinco maneras de morir en Mauthausen", se utiliza una cita de Los sueños de Quevedo, aunque en este caso la muerte viste una "gorra de las SS" (Llorente y Ripoll, 2014: 30). Este texto canonizado del Siglo de Oro representa una tradición literaria española que se emplea en este caso para desvelar la barbarie cometida. Es decir, aquella tradición de la que se ha tratado de expulsar a los españoles que se encuentran encerrados en 
Mauthausen se transforma precisamente en un medio para reafirmarse como españoles y encontrar una explicación del horror vivido. Los presos se reapropian de una tradición negada por su ausencia de patria, ya que Franco se despreocupó de ellos y los dejó en manos de Hitler. De hecho, precisamente el triángulo azul, que da título a la obra, identificaba en los campos de concentración a los presos como apátridas. Muchos de estos españoles, a pesar de que en otras circunstancias llevarían el triángulo rojo por ser presos políticos, tuvieron que lucir el azul con una ' $S$ ' de Spanier. Se crea, en este caso, un fenómeno opuesto al que se contemplaba en los números musicales, y ya no solo se reivindica una tradición popular, sino que también se reclama una tradición culta que legítimamente les pertenece.

En definitiva, esta obra trata de utilizar el metateatro mediante lo grotesco y la risa incómoda para mostrar ese documento contra-cultural de una manera análoga a lo que una vez significaron las fotografías extraídas del campo de concentración de Mauthausen. Mediante este proceso de memoria histórica realizado en escena se ofrece al espectador la posibilidad de escoger entre dejarse llevar por el humor o por la reflexión de la barbarie ocurrida. A pesar de que, nuevamente, las víctimas de la Historia no se pueden salvar de su muerte, se abre una ventana por la que mirar y no cometer los errores del pasado mediante la rememoración.

\section{Conclusiones}

Tras haber analizado cada obra se presentan una serie de convergencias y divergencias entre ellas. Se puede observar una intención de distanciamiento en ambas provocada por una ruptura de la cuarta pared. En ambos casos, los personajes se comunican con el público en una interrupción del orden lógico de la fábula. De esta manera, la mediación entre público y espectáculo se produce por un personaje que participó de la barbarie. Por lo tanto, queda a decisión del espectador fiarse o no del personaje.

En el caso de El triángulo azul, este interlocutor es mediante el que se filtra la ficción, siendo un "narrador" poco fiable. Al mismo tiempo, en Himme/weg esta desestabilización sucede porque el Comandante y el Delegado pueden convertirse en personajes bastante convincentes. La diferencia fundamental en 
este aspecto deriva de que la obra de Mayorga no realiza ningún juicio moral evidente, sino que más bien intenta poner al espectador en una postura comprometida frente a su creencia de que el horror nunca volverá a adquirir semejantes proporciones. En oposición, en El triángulo azul se condena explícitamente la barbarie cometida en el campo de concentración mediante el suicidio final de Ricken.

A pesar de todo ello, ambas cumplen con la idea mayorguiana de concebir el teatro como asamblea, ya que como dice el propio dramaturgo "no es insignificante que el teatro nos entregase la forma de hemiciclo que luego se ha impuesto como dominante en los parlamentos del mundo" (Sánchez Hernández, 2018). Esta idea se afianza porque el Delegado, el Comandante y Ricken ficcionalizan al espectador y se dirigen directamente a él. El público se erige como último eslabón para que lo ocurrido en las tablas tenga un valor social y reformador. Si el espectador no se ve apelado como sociedad, la muerte simbólica de las víctimas, de la que habla Walter Benjamin, continúa perpetrándose.

El sentido, tanto semántico como direccional, de las obras se favorece por el uso de distintos planos espaciales y temporales. Los no-lugares de los monólogos de Himmelweg o los espacios oníricos anacrónicos de El triángulo azul se utilizan como medios para potenciar el carácter metateatral de las obras, así como para poder retratar la verdad oculta ya sea por representación o por omisión de ella. Esta imprecisión cronotópica convierte al espectador en testigo de la barbarie. Los acontecimientos de las obras poseen un valor universal con vigencia en la actualidad, a pesar de que el hecho histórico plasmado se distancie con los años. Todo ello conecta con otra idea del filósofo alemán que consiste en que todos los hombres somos contemporáneos, la barbarie cometida en el pasado es constante y solo se puede detener activamente al ser conscientes continuamente, pues el Delegado habla tanto en Alemania después de la Segunda Guerra Mundial, como en España el día en que se representa la obra.

Se confirma, igualmente, que la música adquiere un valor como elemento de pervivencia de la Memoria en ambas obras. Tanto las canciones de los 
republicanos como la nana de Rebeca se postulan como momentos de presente pleno o tiempo mesiánico en los que se conecta a los hombres del pasado con los espectadores de hoy en día. De nuevo, se incluye al espectador en esta capacidad de poder evitar una segunda muerte simbólica de los oprimidos. Queda en manos de cada uno de nosotros la posibilidad de que esa barbarie se siga perpetrando sobre los muertos o que, sin embargo, podamos salvar del Olvido a los judíos, los españoles republicanos, y a otros colectivos que también fueron víctimas de esta realidad, como la orquesta de gitanos.

En este sentido, cabe remarcar la dualidad que se crea entre alta cultura y cultura popular, sobre todo en El triángulo azul. La música de Wagner o Bach se relaciona con el bando nazi, mientras que la música de verbena o de nana, composiciones de tipo popular, se vincula con las víctimas, ya sean judías o españolas. Esto tiene una gran relevancia, pues rompe con la idea proveniente de la llustración de que la cultura nos libra de la barbarie. El individuo como ser social solo se puede separar de la barbarie gracias al ejercicio crítico con respecto del documento opresor en que se convierte la cultura. Esta consecuencia se concibe desde la construcción de las obras pensando en la metateatralidad como motor hacia esa reflexión.

Al aparecer la metateatralidad como núcleo de las obras, no hay que olvidar los referentes del Siglo de Oro plasmados en las ficciones. En Himmelweg se utiliza el teatro de Calderón para apoyar la posición ilustrada de que la cultura nos libra de la barbarie, mientras que en El triángulo azul aparece como intertexto una obra de Quevedo para el fin opuesto: desvelar la barbarie mediante la exposición de lo vivido en el campo. Se observan, pues, los diferentes usos que se dan a los materiales artísticos por los personajes: en el primer caso se aplica como ocultación de la barbarie, mientras que en el segundo se contempla una intención de resistencia contra el Olvido y las normas estipuladas por la Historia.

En definitiva, a pesar del acercamiento desde distintas estéticas, el empleo de mecanismos metateatrales se lleva a cabo en estas dos obras como recurso dramático para desvelar una historia omitida desde los relatos oficiales y tratar de librar del Olvido a las voces acalladas. Esto sugiere pensar la posible creación de un patrón dentro del "teatro de la memoria" español que utiliza el 
metateatro como aparato para desactivar el artificio, pues ambas obras se constituyen como ficciones que ayudan a crear una memoria colectiva que desvela el pasado y permite avanzar al futuro. Sin duda, Laila Ripoll, Mariano Llorente y Juan Mayorga se sitúan de parte de la contra-cultura y la memoria de los olvidados en un acto ilocutivo frente a la violencia de la Historia.

\section{BiBLIOGRAFÍA}

Amo SÁnchez, Antonia (2020). De Plutón a Orfeo: los campos de concentración en el teatro español contemporáneo (1944-2015). [Inédito].

AzNAR Soler, Manuel (2016). "La recepción crítica del estreno de Himmelweg, de Juan Mayorga, en Madrid", Caracol, 12, 180-205 pp.

CEnTRo DramÁtico NACIONAL (2013). "Entrevista con Laila Ripoll”. En Cuaderno Pedagógico $n^{\circ}$ 32: Autores de hoy II. Madrid: Centro Dramático Nacional, 24-25 pp.

CABAL, Fermín (2009). Dramaturgia española de hoy. Madrid: Autor.

CORNAGo BERNAL, Óscar (2005). "La teatralidad como paradigma de la Modernidad: una perspectiva de análisis comparado de los sistemas estéticos en el siglo XX", Hispanic Research Journal, 6, 2, 155-170 pp.

Cornago Bernal, Óscar (2003). Pensar la teatralidad: Miguel Romero Esteo y las estéticas de la modernidad. Madrid: Fundamentos.

CORNAGo BERNAL, Óscar [1999] (2000). La vanguardia teatral en España (19651975): del ritual al juego. Madrid: Visor.

Di PASTENA, Enrico (2010). "El reloj y la canción: la dimensión metatextual en Himmelweg", Annali dell'Istituto Orientale di Napoli —sezione Romanza, 52, 1-2, 29-57 pp.

GABRIELE, John P. (2014). Lecturas globales del teatro español del siglo XXI. Madrid: Fundamentos.

JódAR PEINADO, María Pilar (2016). Metateatro español en el umbral del siglo $X X I$ : el mundo del teatro y el teatro del mundo. Madrid: Academia de las Artes Escénicas de España.

JOHNSON, Jerelyn (2016). "La doble función de la canción de cuna de Himmelweg de Juan Mayorga”. En José Romera Castillo, Francisco Gómez Cargajo y Raquel García Pascual (eds.), Teatro y música en los inicios del siglo XXI. Madrid: Verbum, 298-306 pp.

LLORENTE, Mariano y RIPOLL, Laila (2014). El triángulo azul. Madrid: Centro Dramático Nacional.

MATE, Reyes (2009). Medianoche en la historia: comentarios a las tesis de Walter Benjamin «Sobre el concepto de historia». Madrid: Trotta.

MATE, Reyes y MAYORGA, Juan (2001). "'Los avisadores del fuego': Franz Rosenzweig, Walter Benjamin y Franz Kafka", Isegoria: Revista de filosofía moral y política, 23, 45-68 pp.

MAYORGA, Juan (2016). Elipses. Segovia: La uña rota.

Mayorga, Juan (2011). Himmelweg. ed. Manuel Aznar Soler. Ciudad Real: Ñaque. 
OÑORO OTERo, Cristina (2016). "Cuando no bastan las palabras. La utilización de la música en El triángulo azul, de Laila Ripoll”. En José Romera Castillo, Francisco Gómez Cargajo y Raquel García Pascual (eds.), Teatro y música en los inicios del siglo XXI. Madrid: Verbum, 236-246 pp.

PAVIS, Patrice [1996] (1998). Diccionario de teatro. Jaume Melendres (trad.). Barcelona: Paidós.

RECK, Isabelle (2012). "El teatro grotesco de Laila Ripoll, autora", Signa: revista de la Asociación Española de Semiótica, 21, 55-84 pp.

SÁNCHEZ HERNÁNDEZ, Pablo (2018). "Entrevista a Juan Mayorga”. [Inédito].

SANCHIS SINISTERRA, José (2002). "Una propuesta del autor". En Terror y miseria en el primer franquismo. Cuadernos Pedagógicos. Madrid: Teatro Común, 9-10 pp.

TRECCA, Simone (2016). "Funciones dramatúrgicas de la música en las puestas en escena de Cancionero republicano y El triángulo azul, de Mariano Llorente y Laila Ripoll”. En José Romera Castillo, Francisco Gómez Cargajo y Raquel García Pascual (eds.), Teatro y música en los inicios del siglo XXI. Madrid: Verbum, 247-258 pp.

Fecha de recepción: 8 de enero de 2020

Fecha de aceptación: 31 de marzo de 2020 